\title{
Direct or Direct-Like Stenting in Acute Stemi with High-Grade Thrombus: A Clinical Case Series
}

\author{
Rohit Mody ${ }^{*}$, Debabrata Dash², Bhavya Mody ${ }^{3}$, Aditya Saholi ${ }^{4}$, Shubham Sachdeva $^{5}$ \\ ${ }^{1}$ Department of Cardiology, Max Super specialty hospital, Bathinda, Punjab, India. ORCID - https://orcid.org/0000-0001-8977-5803 \\ ${ }^{2}$ Department of Cardiology, Zulekha Hospital, AL Zahra Street, Sharjah - 457, UAE. ORCID - https://orcid.org/0000-0003-1354-3808 \\ ${ }^{3}$ Department of Medicine, Kasturba medical college, Manipal, Karnataka, India. ORCID - https://orcid.org/0000-0001-8944-9418 \\ ${ }^{4}$ Department of Medicine, Irwin Hospital, Malout, Punjab, India. ORCID - https://orcid.org/0000-0001-7545-5833 \\ ${ }^{5}$ Department of Medicine, Max Super specialty hospital, Bathinda, Punjab, India. ORCID - https://orcid.org/0000-0001-5052-5102
}

*Corresponding Author: Rohit Mody, Department of Cardiology, Max Super specialty hospital, Bathinda, Punjab, India

Received Date: May 17, 2021; Accepted Date: June 21, 2021; Published Date: June 25, 2021

Citation: Rohit Mody, Debabrata Dash, Bhavya Mody, Aditya Saholi, Shubham Sachdeva. (2021) Direct or Direct-Like Stenting in Acute Stemi with High-Grade Thrombus: A Clinical Case Series. J. Clinical Cardiology and Cardiovascular Interventions, 4(13); Doi:10.31579/2641-0419/184

Copyright: (c) 2021 Rohit Mody, This is an open-access article distributed under the terms of the Creative Commons Attribution License, which permits unrestricted use, distribution, and reproduction in any medium, provided the original author and source are credited.

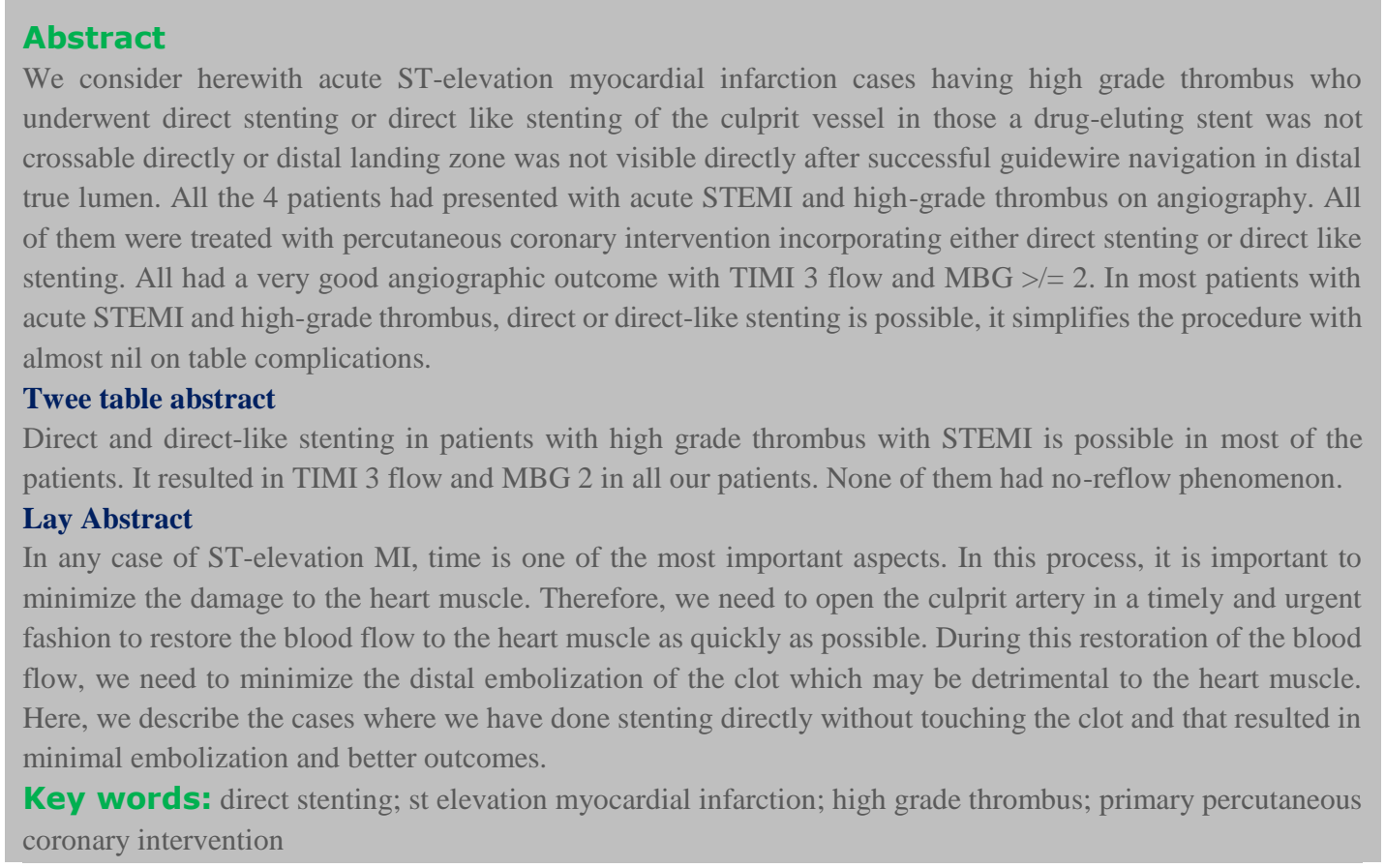

\section{Introduction}

Primary percutaneous intervention (PCI) is nowadays the preferred reperfusion strategy in patients with ST-Elevation myocardial infarction (STEMI) which aims to restore both epicardial flow and achieve microvascular perfusion at the earliest. This limits the extent of irreversible myocardial injury [1].

However, with primary PCI emerging as the gold standard, new questions are arising-

- Could reperfusion damage be prevented?

- What is the mysterious no-reflow phenomenon?
- How can distal coronary embolization be prevented? [2]

Due to these findings, there was an interest in the development of procedural device-based strategies to minimize distal embolization. Among the most studied strategies are distal protection devices, aspiration thrombectomy, and direct stenting [3].

Direct stenting is another method by which we can prevent distal embolization by fixing loose material to the vessel wall that otherwise might have been dislodged during lesion preparation which might have caused distal embolization [4] in the setting of myocardial infarction, there are only five small trials with 754 patients enrolled that compared direct stenting with conventional stenting, which have been summarized 
in a recent meta-analysis [5]. Direct stenting as compared with conventional stenting, improved reperfusion as evidenced by a significant improvement of ST-resolution and a significant reduction in no-reflow, and was also associated with a significant reduction of in-hospital mortality. Still, there is uncertainty because of the small sample size in these trials. And, the use of DES and adjunctive medical therapy was scarce [3]. In this case series, our patients treated with timely PCI using DS or Direct like stenting indicate that this therapy is useful in reducing no-reflow, improving TIMI flow, nil on-table complications, which might translate into better long-term outcomes

\section{Case Presentations}

\section{CASE 1}

A 57-year-old male patient came with a history of Non-Insulin Dependent Diabetes Mellitus (NIDDM) for 5 years, hypertension for 3 years, and dyslipidemia for 3 years with normal body weight. He presented in the emergency room (ER) with a history of chest pain consistent with angina of 6-hour duration. On admission, the patient's vitals were stable, blood pressure (BP) of 130/80 mm of $\mathrm{Hg}$, heart rate of 85 beats per minute (bpm), respiratory rate of 20 breaths/minute, $\mathrm{SpO} 2$ of $95 \%$. The patient's electrocardiography (ECG) and echocardiography (ECHO) showed ST elevation in anterior leads, regional wall motion abnormalities (RWMA) in left anterior descending (LAD) territory, and ejection fraction (EF) $28 \%$ respectively. Coronary angiography $(\mathrm{CAG})$ done through radial approach, revealed single vessel disease with $100 \%$ lesion of proximal LAD having grade 5 thrombus (Figure 1A).

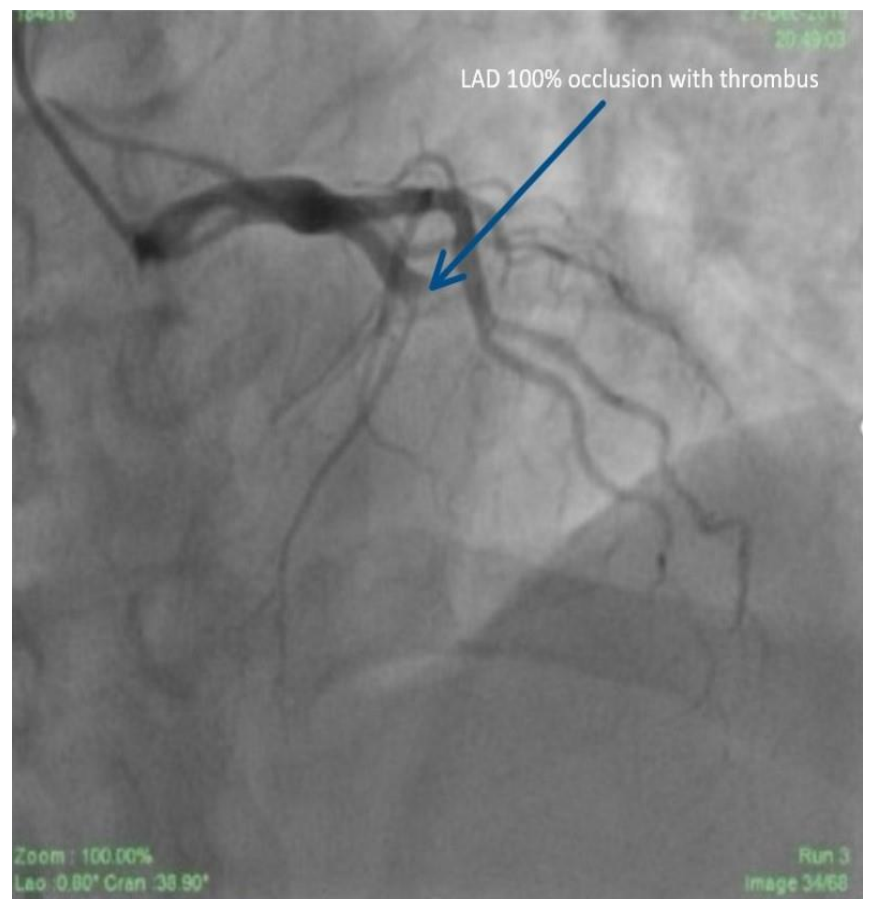

Figure 1: Pre and Post stent coronary angiography (CAG) of Patient 1. Caption -1A: CAG of patient 1 showing 100\% lesion in left anterior descending (LAD) with clot

He was taken up for primary PCI through the radial approach promptly. Before primary PCI $300 \mathrm{mg}$ aspirin and $180 \mathrm{mg}$ ticagrelor were administered. Also, an IV bolus of 70 units $/ \mathrm{kg}$ of heparin and $25 \mathrm{ug} / \mathrm{kg}$ bolus of tirofiban was administered. Tirofiban was continued as an intravenous (IV) infusion at a dose of $0.15 \mathrm{ug} / \mathrm{kg} / \mathrm{min}$ for 24 hours. The left main coronary artery (LMCA) was cannulated with an extra back-up (EBU) 3.5 guiding catheter (Medtronic). The lesion was crossed with a BMW guidewire (Boston scientific corporation). After crossing the guidewire, there was a thrombolysis in myocardial infarction (TIMI) 1 grade flow.

We could assess the distal landing zone. Despite heavy clot burden, we deployed a 3 x $38 \mathrm{~mm}$ drug-eluting stent (DES) (Cobalt-chromium everolimus-eluting stent; Xpedition; Abbott Vascular, Santa Clara, California, USA) directly at 16 atm. Post-procedure scores of TIMI 3 flow and myocardial blush grade (MBG) 2 were obtained (Figure 1B).

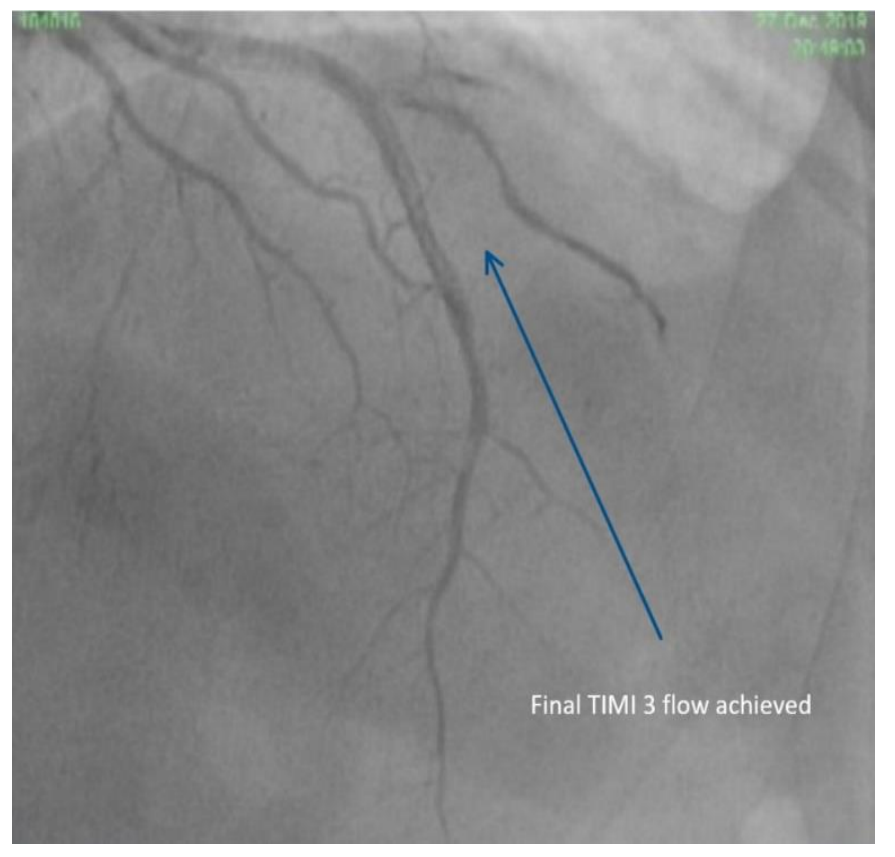

Caption -1B: Post stent CAG showing thrombolysis in myocardial infarction (TIMI) 3 flow.

The patient's vitals remained stable throughout the procedure (Table 1). The patient was discharged with a prescription of lisinopril, bisoprolol, aspirin, ticagrelor, and rosuvastatin. On follow-up at seven days, the patient was clinically examined in the out-patient department. The patient was asymptomatic and free of angina. ECG showed QS from V1 to V6 with settled ST segments and ECHO revealed an improved EF of $35 \%$. The last follow-up at 6 months was uneventful. ECHO showed an improved EF of $46 \%$. Ticagrelor was discontinued after one year.

\section{CASE 2}

A 70-year-old female came with a history of NIDDM, hypertension, and dyslipidemia for the past 10 years with normal body weight. She presented in the ER with complaints of chest pain consistent with angina of 12-hour duration. On assessment, the patient was breathless and hypotensive with a respiratory rate of 27 breaths/minute and BP of $80 / 50 \mathrm{~mm}$ of $\mathrm{Hg}$. Bilateral basal crepitations were present. Norepinephrine infusion was started at 3 micrograms $/ \mathrm{kg} /$ minute and increased up to $10 \mathrm{mcg} / \mathrm{kg} /$ minute. The patient was started on furosemide infusion for the pulmonary edema. Patient mentation was normal, with slightly cold peripheries and adequate urine output. The patient's ECG and ECHO showed ST elevation in anterior leads RWMA in LAD territory and EF $26 \%$ respectively. After her vitals were stable, she was taken up for PCI. CAG was done immediately and revealed single vessel disease with $99 \%$ lesion of proximal LAD having grade 3 clot (Figure 2A). 


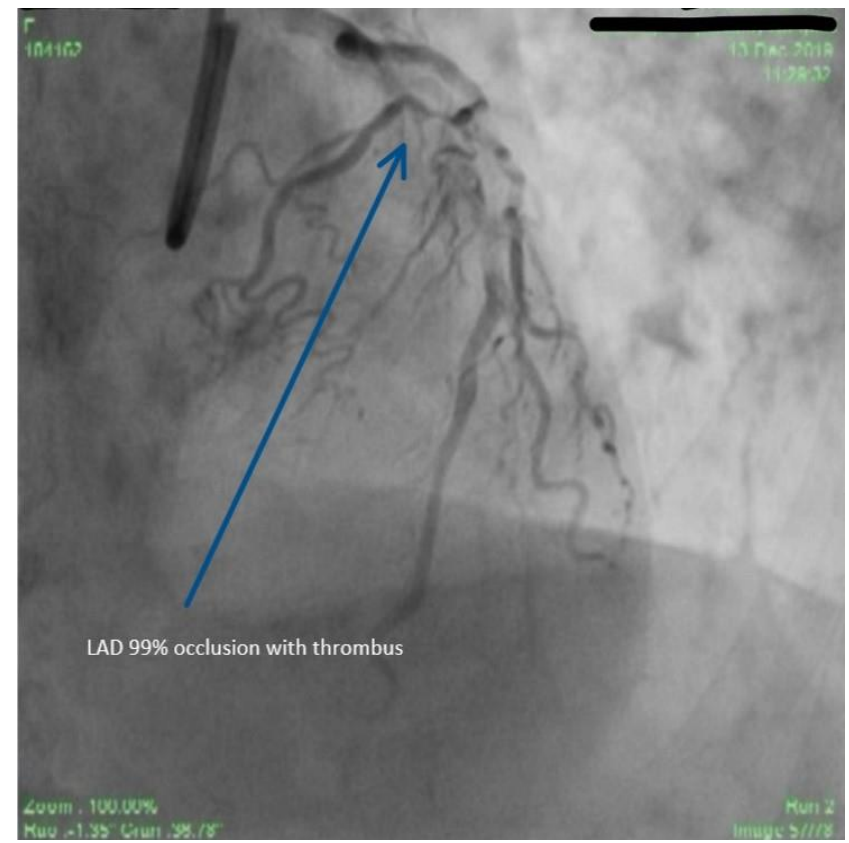

Caption - 2A: CAG of patient 2 showing 99\% lesion of Proximal LAD Figure 2: Pre and Post stent CAG of Patient 2

Before PCI $300 \mathrm{mg}$ aspirin and $180 \mathrm{mg}$ ticagrelor were administered. Also, tirofiban and heparin were given in the same dose as Case 1. Tirofiban was continued as an IV infusion at a dose of $0.15 \mathrm{ug} / \mathrm{kg} / \mathrm{min}$ for 24 hours.

6F EBU 3 guide catheter (Medtronic) was used to engage LMCA. The lesion in LAD was crossed with a BMW guidewire (Boston scientific corporation) and a 3 x $28 \mathrm{~mm}$ DES (Cobalt-chromium everolimus-eluting stent; Xpedition; Abbott Vascular, Santa Clara, California, USA) was deployed directly at 16 atm for 30 minutes. The length could be assessed as the distal landing zone was visible. Post-procedure there was TIMI 3 flow and MBG 3 (Figure 2B).

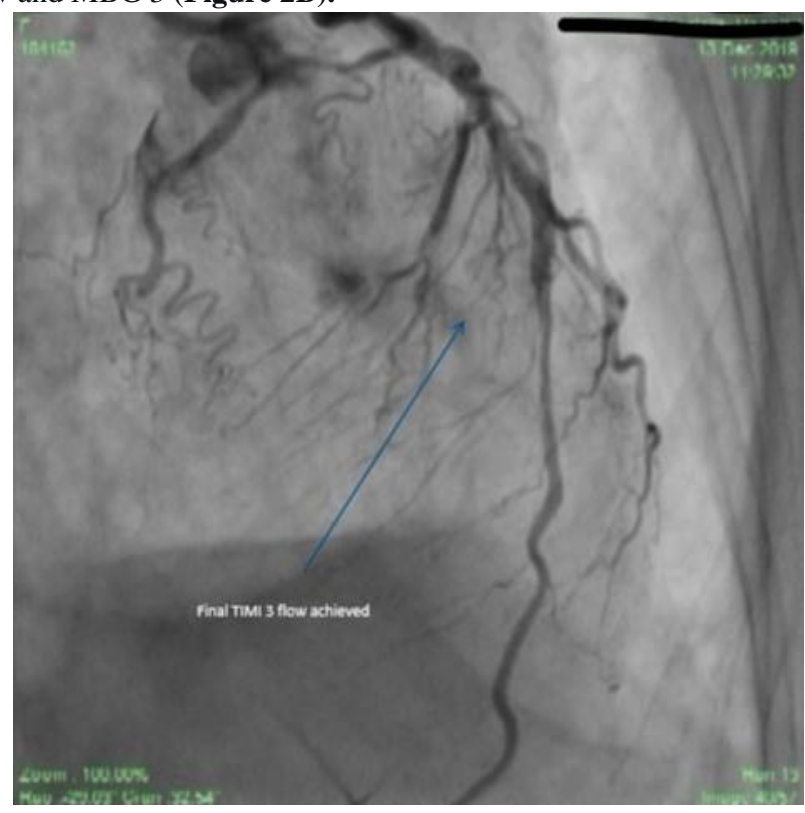

Caption 2B: Post stent CAG showing TIMI 3 Flow
The patient's vitals remained stable throughout the procedure (Table 1). The patient was shifted to the cardiac care unit for observation. On day three, the patient was assessed for signs of decreased myocardium perfusion. ECG showed QS from V1 to V6 with settled ST segments and ECHO revealed EF of $28 \%$. The patient was discharged with a prescription of lisinopril, bisoprolol, aspirin, ticagrelor, and rosuvastatin. At three months' follow-up, the patient was asymptomatic and free of angina. The last follow-up at 6 months was uneventful. ECHO showed an improved EF of $44 \%$. Ticagrelor was discontinued after one year.

\section{CASE 3}

A 65-year-old obese female, with a body mass index (BMI) of 36, dyslipidemic for 5 years, presented to ER with a history of chest pain of 36-hour duration. ECG showed ST elevation in inferior leads. Vitals at the time of admission were stable with a heart rate of $90 \mathrm{bpm}, \mathrm{BP}$ of $110 / 70 \mathrm{~mm}$ of $\mathrm{Hg}$, and respiratory rate of 16 breaths/minute. ECHO showed RWMA in the inferior-posterior wall with an EF of $40 \%$ without mitral regurgitation (MR). The patient was taken for PCI in a timely fashion. Her CAG revealed single-vessel disease involving right coronary artery (RCA) - 100\% lesion of proximal RCA with grade 5 clot (Figure 3A).

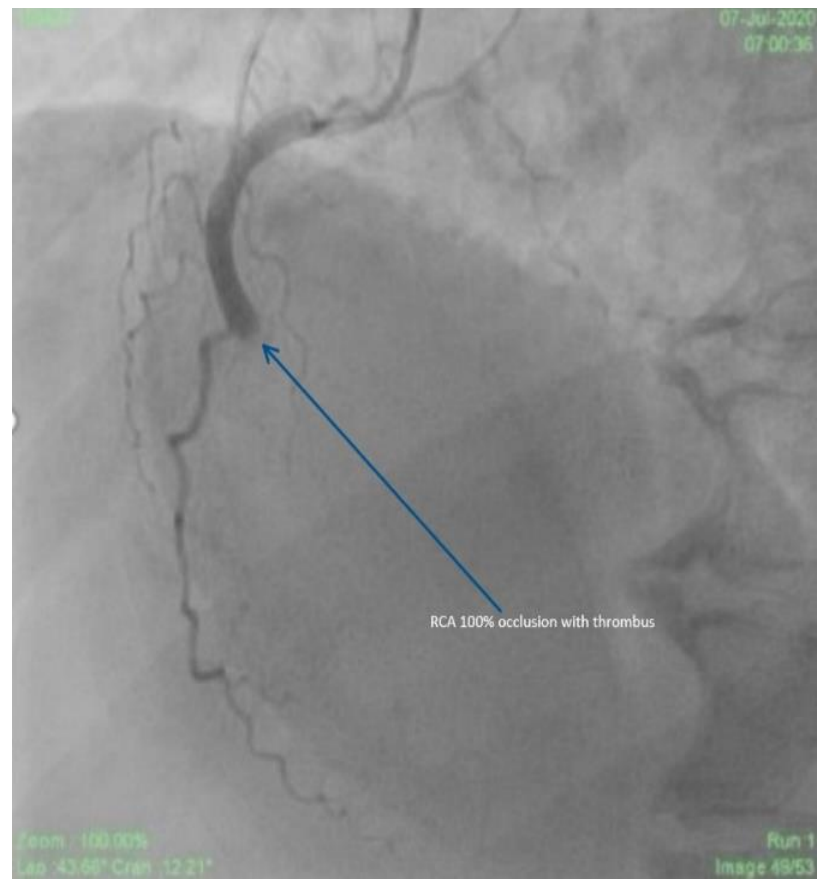

Figure 3 Title - Pre and Post stent CAG of Patient 3

Caption - 3A - CAG of Patient 3 showing 100\% lesion of proximal right coronary artery (RCA)

Before PCI $300 \mathrm{mg}$ aspirin and $180 \mathrm{mg}$ ticagrelor were administered. Also, tirofiban and heparin were given in the same dose as Case 1. Tirofiban was continued as an IV infusion at a dose of $0.15 \mathrm{ug} / \mathrm{kg} / \mathrm{min}$ for 24 hours.

A 6 F JR 3.5 guiding catheter (Medtronic) was used to engage RCA. The lesion was crossed with a BMW guidewire (Boston scientific corporation) and a 3 x $26 \mathrm{~mm}$ DES (Cobalt-chromium everolimus-eluting stent; Xpedition; Abbott Vascular, Santa Clara, California, USA) was implanted directly at 16 atm. Post-procedure there was TIMI 3 flow and MBG 3 (Figure 3B). 


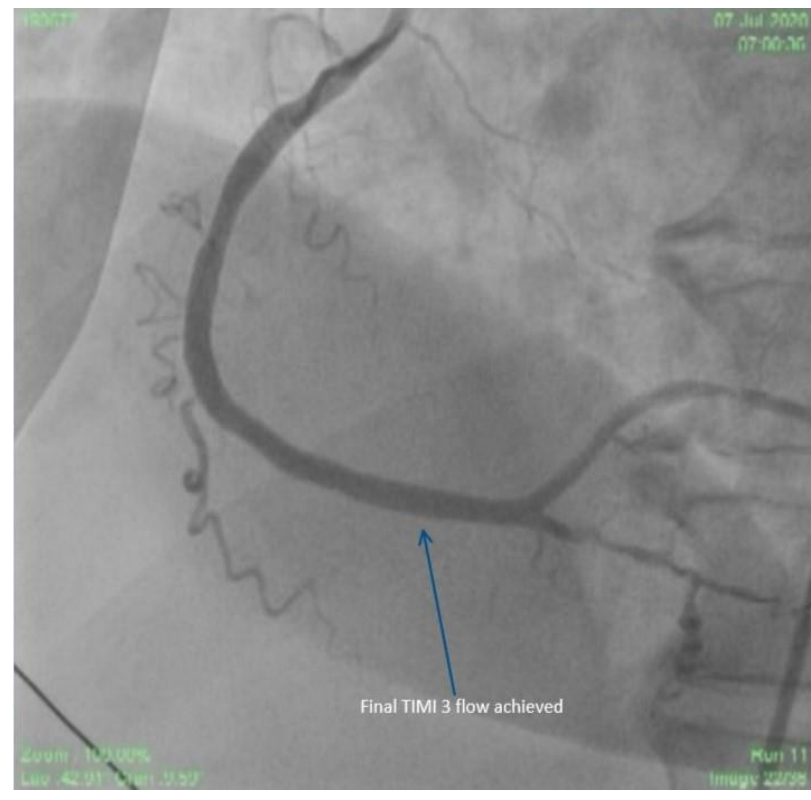

Caption -3B: Post stent CAG showing TIMI 3 Flow

The patient's vitals remained stable throughout the procedure (Table 1). Just a day after the procedure, ECHO revealed an improved EF of $44 \%$ which further increased to $45 \%$ by day three (Table 1).

The patient was discharged with a prescription of lisinopril, bisoprolol, aspirin, ticagrelor, and rosuvastatin with advice to follow-up at 7 days, one month, three months, six months, and one year. Ticagrelor was discontinued after one year.

\section{CASE 4}

A 60 -year-old obese $(\mathrm{BMI}=34)$ male dyslipidemic for the last 10 years, without any history of diabetes and hypertension presented in ER with a history of chest pain consistent with angina of 20-hours duration. On examination, the heart rate was $92 \mathrm{bpm}$ with a $\mathrm{BP}$ of $108 / 72 \mathrm{~mm}$ of $\mathrm{Hg}$ and respiratory rate of 17 breaths/minute. His ECG showed ST elevation in anterior leads and ECHO revealed RWMA in LAD territory with EF $28 \%$. The patient was taken for PCI in a timely fashion. CAG was done immediately and revealed single vessel disease with $100 \%$ lesion of proximal LAD grade 5 thrombus (Figure 4A).

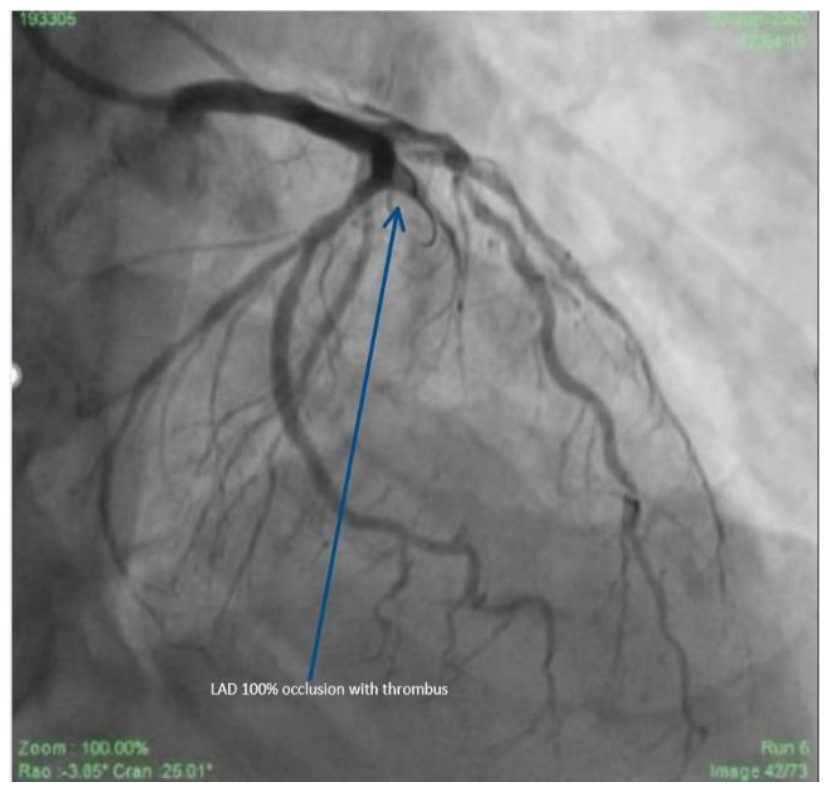

Figure 4 Title - Pre and Post stent CAG of Patient 4

Caption - 4A: CAG of patient 4 showing 100\% lesion in LAD with clot

Before PCI $300 \mathrm{mg}$ aspirin and $180 \mathrm{mg}$ ticagrelor were administered. Also, tirofiban and heparin were given in the same dose as Case 1. Tirofiban was continued as an IV infusion at a dose of $0.15 \mathrm{ug} / \mathrm{kg} / \mathrm{min}$ for 24 hours.

LMCA was hooked with 6F EBU 3.5 guiding catheter (Medtronic). The lesion was crossed with a BMW guidewire (Boston scientific corporation) but the stent could not cross the lesion directly. Hence, a small 1.25 x12 $\mathrm{mm}$ balloon (AccuForce; Terumo) was used to create a small passage to just visualize the distal landing zone (direct like stenting). Subsequently, $2.5 \times 45 \mathrm{~mm}$ and $3 \times 44 \mathrm{~mm}$ DES (Cobalt-chromium everolimus-eluting stent; Xpedition; Abbott Vascular, Santa Clara, California, USA) were implanted distally and proximally at 18 atm respectively. Post-procedure there was TIMI 3 flow and MBG 2 (Figure 4B).

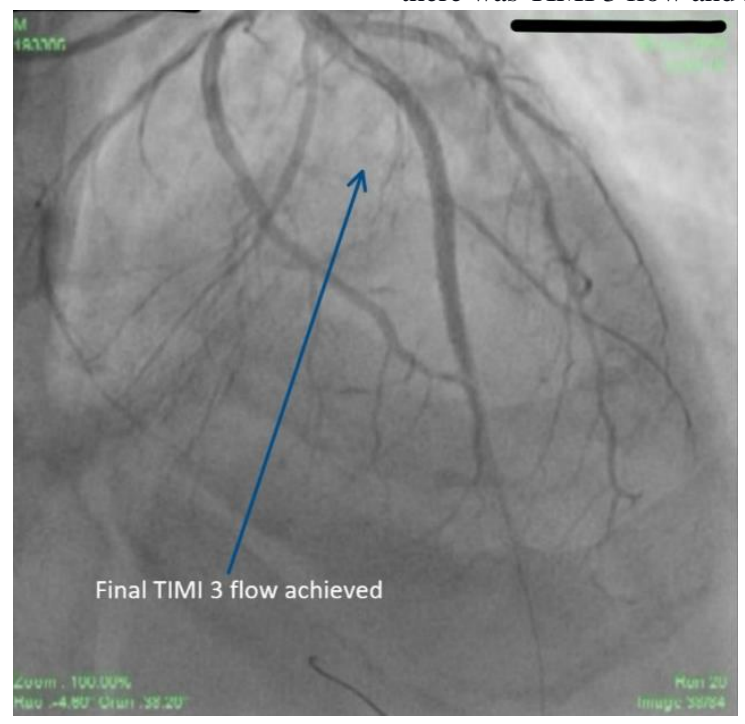

Caption - 4B: Post stent CAG showing TIMI 3 Flow 


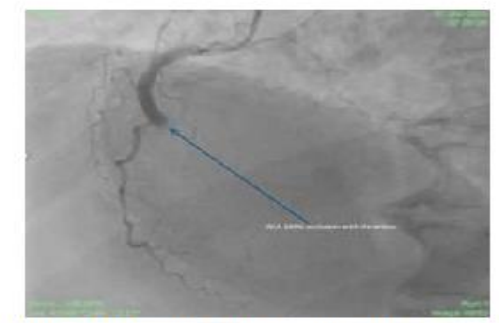

RCA 100\% Blocked with clot grade 5.

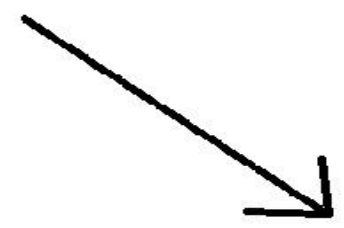

Direct or Direct like stenting simplifies the procedure with TiMi-3 flow, no-reflow and nil on-table complications.

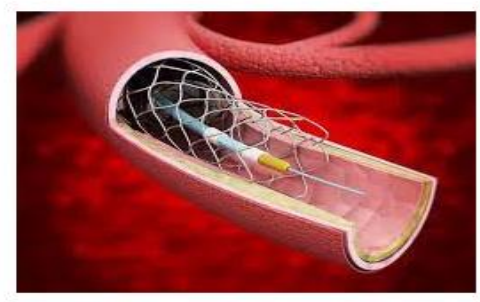

\section{Graphical Abstract}

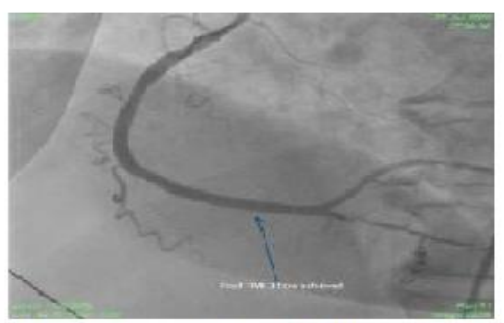

TiMi-3 flow achieved with no reflow and nil on table complications.

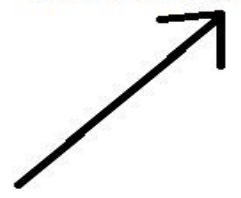

The recovery was uneventful without any complication (Table 1). ECHO after 24 hours of the procedure showed EF of 30\%. At discharge, after 3 days EF was $35 \%$. The patient was discharged with a prescription of lisinopril, bisoprolol, aspirin, ticagrelor, and rosuvastatin and advice for regular follow-ups. ECHO was repeated at the six months' follow-up visit and revealed an EF of $41 \%$. Ticagrelor was discontinued after one year.

\section{Discussion}

In patients with STEMI undergoing PCI, several strategies have been used to improve myocardial reperfusion. Direct stenting has been shown to decrease distal embolization and microvascular obstruction in some of the studies [6]. The strategy is widely practiced although no formal guidelines or recommendations for it exist [7]. In a study by Thrombectomy Trialist Collaboration [8], direct stenting was not associated with improved 30 day or 1-year clinical outcomes as compared to conventional stenting, but in this data patients on whom direct stenting was done, many patients had thromboaspiration done before the stenting. Of note, it has been observed that thrombus aspiration during PCI before direct stenting may cause distal embolization as well due to the dottering effect of the thrombectomy device itself. 'The risk of distal embolization, especially during a hurried maneuver or the inevitable multiple passes required in a large thrombus, cannot be dismissed' [9]. Hence the effect of direct stenting for preventing distal embolization could not have been fully exploited.

The Thrombectomy Trialists Collaboration [8] performed the largest observational study comparing direct stenting with conventional stenting during PPCI. They also addressed its interaction with aspiration thrombectomy [10]. In this study, 32\% of the 17329 patients included underwent direct stenting. Direct stenting was performed more often in patients who underwent aspiration thrombectomy as compared to those with conventional PCI ( $41 \%$ vs. $22 \%$; P < 0.001). In Direct stenting, the use of contrast was less and the fluoroscopy time was shortened $(\mathrm{P}<0.001$ for both comparisons). It is to be seen whether this benefit would be seen in patients who do not need aspiration thrombectomy before direct stenting. To compensate for the non-randomized nature of the comparison, propensity matching was performed, resulting in an analysis cohort of 10944 patients. Comparing direct stenting with conventional stenting, the analysis did not yield any evidence of the benefit or harm of direct stenting.

Specifically, 30-day incidences of cardiovascular death or cerebrovascular events were low and not significantly different between direct stenting and conventional stenting (1.7\% vs. $1.9 \%)$. There were no significant differences in all-cause mortality, myocardial infarction, and stent thrombosis. The 1-year incidence of vessel revascularization was lower after direct stenting than after conventional stenting $(4.3 \%$ vs. $5.6 \%)$. Nevertheless, this finding is important. It has been previously believed that direct stenting may result in inadequate sizing of the stent resulting in an increased risk of stent thrombosis and restenosis. But the current analysis makes these concerns insignificant by showing a trend in the opposite direction. In TAPAS [11] and TOTAL [12] 6534 propensitymatched patients, incomplete ST-segment resolution $(<70 \%)$ was less frequent after direct stenting than after conventional stenting (3\% vs. $35 \%$ ) as was the proportion of patients with myocardial blush grade 0 or $1(4.7 \%$ vs. $5.7 \%)$. But in these trials, they have used a thrombectomy device before doing direct stenting in a large number of patients and as noted previously, thrombectomy itself may predispose to distal embolization. The potential of DS might not have been fully exploited.

Only a trend towards improved ST-segment resolution by direct stenting was noted $(\mathrm{P}=0.06)$. Thus, the current analysis failed to prove a favorable effect of direct stenting on myocardial perfusion which had been the putative mechanism for a clinical benefit. There is no doubt that distal protection devices capture embolized material during PPCI and that aspiration thrombectomy removes thrombus and reduces thrombus burden; it is also highly intuitive that direct stenting reduces distal embolization. A positive effect of these measures on distal reperfusion, however, has been hard to demonstrate. By the time of PPCI, the STEMI has already caused prior distal embolization of thrombus and plaque. Reperfusion injury may worsen this. Thus, only one among the many elements of reperfusion in STEMI can be modified by using device-based strategies. In the current era of optimized PCI and adjunctive treatment, this limited effect may not translate into a meaningful clinical benefit. As 
the mortality in uncomplicated STEMI is already very low- $1.8 \%$ at 30 days and $2.9 \%$ at 1 year, it is very hard to show further improvement [3].

But the positive effects of DS cannot be denied. In a recent article, it has been concluded that in patients with acute reperfused STEMI, DS is safe and feasible with a significant reduction of infarct size compared to CS and subsequent lower incidence of heart failure hospitalizations and mortality [13]. But some other studies did not show any significant difference between DS and CS [14,15,16,17].

A meta-analysis that included 7 studies comparing DS and CS strategies revealed a lower adverse event rate with DS. Studies included in this meta-analysis were mostly observational and utilized first-generation drug-eluting stents. Patient and lesion selection may explain these positive results $[18,19]$.

Despite high clinical and angiographic risk profile, the Swedish Coronary Angiography and Angioplasty Registry (SCARR registry) established very low rates of clinical restenosis and stent thrombosis (close to $1 \%$ and $0.5 \%$, respectively) while reporting the clinical outcomes in a patient treated with state-of-the-art DES. Thus, we have almost achieved victory in the battle of restenosis. In view of such encouraging outcomes, it seems difficult to obtain a sizeable benefit with the compulsory use of DS [20].

'The meta-analysis - Comparing Direct Stenting with Conventional Stenting in Patients with Acute Coronary Syndromes: A Meta-Analysis of 12 Clinical Trials' demonstrated that in selected patients with ACS, DS is not only safe and feasible but also reduces short-term and 1-year mortality as well as the occurrence of after-procedural no-reflow phenomenon [21].

A predefined sub-study of the LIPSIA CONDITIONING trial was a prospective, controlled, single-center randomized trial investigating the effects of ischemic preconditioning plus postconditioning in STEMI patients undergoing primary PCI. 171 patients who underwent conventional stenting with balloon pre-dilatation were case-matched to 171 patients who underwent direct stenting for age (+ 5 years), sex, and TIMI flow before PCI. Three-vessel coronary artery disease (CAD) was more prevalent in the conventional stenting group and thrombectomy was used more often in the direct stenting group. The results of the study showed that direct stenting resulted in a significantly smaller infarct size on MRI 2-5 days after the index event (16\% vs. $19 \%)$ and a lower 6-month mortality rate (5\% vs. $12 \%)$ [22].

As the mortality of primary angioplasty in recent years has decreased considerably with a mortality of less than $2 \%$ in uncomplicated MI, the subtle effect of DS on mortality might not be easily demonstrable. But this concept should be extrapolated to high-risk patients like patients of STEMI in Cardiogenic shock [23].

The take-home message is that, if direct stenting or direct-like stenting is done in patients with high-grade thrombus in the setting of STEMI, the distal embolization is minimal as observed in these patients. In case direct stenting is not possible, a direct like stenting following pre-dilatation with a small balloon could be performed. In literature also, deflated balloonassisted direct stenting has been reported and has shown to increase the success rate of direct stenting [24]. By using direct stenting, even in patients of high-grade thrombus, we have not used thrombosuction in any of the patients.

\section{Conclusion}

In most patients direct stenting is feasible. In patients in whom stent does not cross or distal vessel landing zone is not visible direct-like stenting can be performed successfully and even thrombosuction can be avoided. Direct or direct-like stenting simplifies the procedure with less contrast used and nil on table complications. TIMI 3 flow is achieved in all and distal embolization is less. However, a proper randomized controlled trial is warranted further to demonstrate if this strategy of direct or direct like stenting without the use of thrombectomy is more useful and has an impact on hard clinical outcomes. In a nutshell, our study and discussion point to a strategy where we should be as direct as possible while dealing with patients of primary PCI in STEMI.

\section{Learning points}

In most patients with acute STEMI and high-grade thrombus, direct or direct-like stenting is possible. Direct or direct-like stenting simplifies the procedure with less contrast used and almost nil on table complications. TIMI grade 3 flow can be achieved more often and the incidence of distal embolization is very less.

\section{Declarations}

\section{Acknowledgements}

None.

\section{Authors' contributions}

Contributions are cited on the title page.

\section{Funding}

No funding has been received for the current study.

\section{Availability of data and materials}

The datasets used and/or analyzed during the current study are available from the corresponding author on reasonable request.

I confirm that all figures and tables are original and created by me specifically for use in this paper.

\section{Ethics approval and consent to participate}

Ethical approval was not required since it is an accepted procedure.

\section{Consent for publication}

Written consent has been obtained to publish the case report from the guardian. The consent copy is available with the authors and ready to be submitted if required.

\section{Competing interests}

The authors declare that they have no competing interests.

\section{References}

1. Niccoli G, Montone RA, Ibanez B, et al. Optimized Treatment of ST-Elevation Myocardial Infarction. Circulation Research. 125:245-58 (2019).

2. Reperfusion damage or no-reflow damage in primary coronary interventions in acute myocardial infarction? European Heart Journal. 23(14):1076-78 (2002).

3. Neumann FJ and Gick M. Direct stenting in ST-elevation myocardial infarction: convenient, but not improving outcomes. European Heart Journal. 39:2480-83 (2018).

4. Loubeyre C, Morice MC, Lefevre T, Piechaud JF, Louvard Y, Dumas P. A randomized comparison of direct stenting with conventional stent implantation in selected patients with acute myocardial infarction. JACC. 39:15-21 (2002).

5. Alak A, Lugomirski P, Aleksova N, Jolly SS. A meta-analysis of randomized controlled trials of conventional stenting versus 
direct stenting in patients with acute myocardial infarction. J Invasive Cardiol. 27:405-409 (2015).

6. Barbato E, Marco J, Wijns W. Direct stenting. European Heart Journal. 24(5):394-403 (2003).

7. Ibanez B, James S, Agewall S, et al. 2017 ESC Guidelines for the management of acute myocardial infarction in patients presenting with ST-segment elevation: The Task Force for the management of acute myocardial infarction in patients presenting with ST-segment elevation of the European Society of Cardiology European Heart Journal. 39(2):119-177 (2018).

8. Mahmoud KD, Jolly SS, James S, et al. Clinical impact of direct stenting and interaction with thrombus aspiration in patients with ST-segment elevation myocardial infarction undergoing percutaneous coronary intervention: Thrombectomy Trialists Collaboration. European Heart Journal. 39(26): 2472-79 (2018).

9. Topaz O, Topaz A, Polkampally PR. Thrombectomy In Acute Myocardial Infarction, Interventional cardiology. 4(1):85-90 (2009).

10. Jolly SS, James S, Džavík V, et al. Thrombus Aspiration in ST Elevation Myocardial Infarction: An Individual Patient Metaanalysis. AHA. 135:143-152 (2018).

11. Svilaas T, Vander Horst ICC, Zijlstra F. Thrombus Aspiration during Percutaneous coronary intervention in Acute myocardial infarction Study (TAPAS) - Study design. Am Heart J. 151:597 (2006).

12. Jolly SS, Cairns AJ, Yusuf S, et al. Design and rationale of the TOTAL trial: A randomized trial of routine aspiration thrombectomy with percutaneous coronary intervention (PCI) versus PCI alone in patients with ST-elevation myocardial infarction undergoing primary PCI. American Heart Journal (2014).

13. Saad M, Stiermaier T, Fuernau G, et al. Impact of direct stenting on myocardial injury assessed by cardiac magnetic resonance imaging and prognosis in ST-elevation myocardial infarction. International J Cardiol. 283:88-92(2019).

14. Gasior M, Gierlotka M, Lekston A, et al. Comparison of outcomes of direct stenting after balloon predilatation in patients with acute myocardial infarction (DIRAMI). Am. J. Cardiol. 100:798-805(2007).

15. Caputo RP, Flately M, Ho KK, Baim DS. Safety and effectiveness of stent implantation without predilation for small coronary arteries. Catheter Cardiovasc Interv. 59(4):455458(2003).

16. Brito FJ, Caixeta AM, Perin MA, et al. Comparison of direct stenting versus stenting with predilation for the treatment of selected coronary narrowings. Am J Cardiol. 89(2):115120(2002).

17. Elbaz M, Mokhtar EE, Khalife K, et al. Is direct coronary stenting the best strategy for long-term outcome? Results of the multicentric randomized benefit evaluation of direct coronary stenting (BET) study. Am Heart J. 144(4):E7(2002).

18. Magalhaes MA, Minha S, Lhermusier T, et al. Does direct stenting with drug-eluting stents improve outcome? A metaanalysis of 10,900 patients. Catheter Cardiovasc Interv. 90:213-222(2017).

19. Belardi JA and Albertal M. Direct stenting versus balloon predilation: Jury is still out. Catheter Cardiovasc Interv. 90:223-224 (2017).

20. Sarno G, Lagerqvist B, Olivecrona G, et al. Real-life clinical outcomes with everolimus eluting platinum chromium stent with an abluminal biodegradable polymer in patients from the Swedish Coronary Angiography and Angioplasty Registry (SCAAR). Catheter Cardiovasc Interv. (2017).

21. Li C, Zhang B, Li M, et al. Comparing Direct Stenting With Conventional Stenting in Patients With Acute Coronary Syndromes: A Meta-Analysis of 12 Clinical Trials. Angiology 1-9. 67(4):317-325 (2015).

22. Yang EH. "Should We Be More Direct With STEMI Patients?". International Journal of Cardiology. (2019).

23. Van't Hof AWJ and Ottervanger JP. Primary angioplasty for STEMI: hard to improve upon. 387(10034):2166-68(2016).

24. Verma B, Singh A, Saxena AK, Kumar M. Deflated BalloonFacilitated Direct Stenting in Primary Angioplasty (The DBDS Technique): A Pilot Study Cardiol Res. 9(5):284-92 (2018).
This work is licensed under Creative Commons Attribution 4.0 License

To Submit Your Article Click Here: Submit Manuscript

DOI: $10.31579 / 2641-0419 / 184$
Ready to submit your research? Choose Auctores and benefit from:

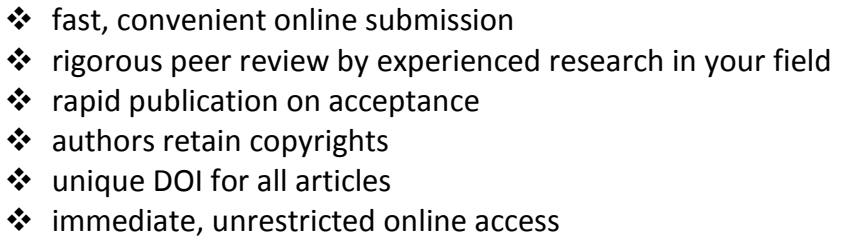

At Auctores, research is always in progress.

Learn more www.auctoresonline.org/journals/clinical-cardiology-andcardiovascular-interventions 